Published in final edited form as:

Hematology Am Soc Hematol Educ Program. 2010 ; 2010: 403-408. doi:10.1182/

asheducation-2010.1.403.

\title{
Neurobiological Mechanisms of Pain in Sickle Cell Disease
}

\author{
Zaijie J. Wang, PhD ${ }^{1}$, Diana J. Wilkie, PhD, RN, FAAN ${ }^{2}$, and Robert Molokie, MD ${ }^{3,4}$ \\ ${ }^{1}$ University of Illinois at Chicago College of Pharmacy Department of Biopharmaceutical \\ Sciences, Chicago, IL \\ ${ }^{2}$ University of Illinois at Chicago College of Nursing Department of Biobehavioral Health Science, \\ Chicago, IL \\ ${ }^{3}$ University of Illinois at Chicago College of Medicine Department of Hematology/Oncology, \\ Chicago, IL \\ 4Jessie Brown Veteran's Administration Medical Center, Chicago, IL
}

\begin{abstract}
Pain is a frequent complaint of people living with SCD. The neurobiology of pain in SCD remains poorly understood. Whereas pain of SCD has been thought to be primarily related to visceral and somatic tissue injury subsequent to vaso-occlusion events, emerging evidence from our human and animal studies has suggested that a component of SCD pain may be related to neuropathic processes. Significant knowledge has been obtained from studies of molecular and neurobiological mechanisms leading to and maintaining neuropathic pain. Some of the most promising evidence has implicated major roles of protein kinase $\mathrm{C}$ and $\mathrm{Ca}^{2+} /$ calmodulin-dependent protein kinase II, and their interaction with of the N-methyl-D-aspartate (NMDA) receptors and the transient receptor potential vanilloid 1 receptor (TRPV1) in the development of neuropathic pain. Latest evidence from our studies suggests that these pathways are important for SCD pain as well. Coupled with the emerging animal models of SCD pain, we can now start to elucidate neurobiological mechanisms underlying pain in SCD, which may lead to better understanding and effective therapies for SCD pain.
\end{abstract}

\section{Keywords}

pain; phosphorylation; protein kinase; PKC; CaMKII; PKA; TRPV1

\section{Introduction}

Pain and sickle cell disease are so intimately intertwined, that African tribal words for the disease, spoken hundreds of years before Herrick described SCD in the western literature ${ }^{1}$, are onomatopoeic for pain. A century since Herrick's paper, ${ }^{1}$ the neurobiology of chronic pain in SCD remains poorly understood. On the other hand, significant research effort has been made in elucidating the neurobiological mechanisms leading to other chronic pain conditions including neuropathic pain. Neuropathic pain is defined as persistent pain resulting from damage to the peripheral or central nervous system or abnormal communication within the nervous system. ${ }^{2}$ This syndrome is often manifest in patients suffering from ailments such as diabetes, herpes zoster, nerve traction or compression, radiation therapy, complex regional pain syndrome, fibromyalgia, and AIDS. Many of these

Correspondence to: Zaijie Jim Wang, Department of Biopharmaceutical Sciences, University of Illinois at Chicago, MC865, Rm 335, 833 S Wood Street, Chicago, IL 60612, Phone: (312) 355-1429; Fax: (312) 413-7792, zjwang @uic.edu. 
patients experience both persistent spontaneous pain and stimulus-evoked pain. The latter is characterized by both allodynia (pain elicited by normally innocuous, low threshold stimuli) and hyperalgesia (enhanced pain response to noxious stimuli). Some recent evidence from our ongoing studies in sickle cell patients as well as sickle cell transgenic models, suggests the presence of neuropathic pain. The finding of neuropathic pain in sickle cell patients is contrary to the common belief that SCD pain is only nociceptive, which may have a profound impact on our understanding and treatment of SCD pain. This article will highlight some of the key advances in the study of molecular mechanisms underlying neuropathic pain that may be relevant to sickle cell pain, with an emphasis on signaling mechanisms involving protein kinases. Some other aspects of mechanisms relative to neuropathic pain, including glial activation, proinflammatory or pronociceptive cytokines, chemokines, receptors and transporters, can be found in several excellent reviews that have been published recently. ${ }^{3-5}$ These mechanisms are largely untested in SCD pain studies.

\section{Neuropathic pain in adult sickle cell disease}

Pain is a frequent complaint of people living with SCD. Nationwide epidemiological survey data indicate that over half of sickle cell patients have 1-2 episodes annually. One percent of patients have more than 10 episodes. ${ }^{6}$ Hospital admissions for acute painful episodes have been reported to be a predictor of prognosis. Moreover, half of those hospital admissions are readmitted within 1 month after discharge. ${ }^{7}$ A more recent study followed diary recordings of SCD patients for up to 6 months and found that $55 \%$ of patients with SCD reported pain on more than half of the diary days and $29 \%$ on $95 \%$ of days. ${ }^{8}$ Risk for mortality in adults with SCD increases for patients with increased rates of painful episodes. ${ }^{6}$ We followed 145 adult SCD patients who completed a computerized McGill Pain Questionnaire (MPQ) in an outpatient sickle cell specialty clinic. These subjects reported an average of 3.6 pain sites. Based on estimated normative MPQ scores, we found that SCD pain was more severe than cancer pain or the pain of labor. ${ }^{40}$ Strikingly, SCD patients selected verbal pain quality descriptors that are consistent with the presence of neuropathic pain. Over $90 \%$ of the 145 patients selected neuropathic pain descriptors and $59 \%$ of the sample reported continuous pain pattern. Our ongoing study using quantitative sensory test (QST) is examining, allodynia and hyperalgesia, the hallmarks of neuropathic pain in these patients. We also found long lasting tactile allodynia and thermal (both cold and heat) hyperalgesia in sickle cell transgenic mice (Chen, Wang et al, unpublished observations).

\section{Nociceptive pain}

Primary afferent nociceptor (PAN), which sense the thermal, mechanical, and chemical stimuli, are the peripheral nerve fibers of pseudounipolar sensory neurons that reside in the trigeminal ganglion (for the face) or the dorsal root ganglion (DRG) (for the body). Sensory neurons receive peripheral pain stimuli from their target organs and transmit the nociceptive signals through their central projections that end in the spinal cord dorsal horns. Depending on the types of nociceptive nerve fibers and pain, different fibers terminate at different layers in the dorsal horn. Damage to visceral and somatic tissue produces a variety of chemicals that cause a neuronal action potential on the PAN. Some chemical byproducts of cellular damage (bradykinin, serotonin, histamine, potassium ions, norepinephrine) stimulate the PAN whereas others (leukotrienes, prostaglandins, substance P) sensitize the PAN to the effects of other mediators of neuronal transduction, which, if of sufficient magnitude, result in an action potential that is then transmitted to the spinal cord. Specifically, when a cell is damaged, phospholipids and other substances are liberated from the cell. The release of phospholipids initiates the arachidonic acid cascade through which 5-lipooxygenase and cyclooxygenase synthesize leukotrienes and prostaglandins, respectively. These events are displayed in Figure 1. Leukotrienes and prostaglandins sensitize the PAN to be activated by a smaller stimulus. For example, light pressure is not perceived as painful in normal 
conditions, but sometimes is sensed as pain (allodynia) if there is an inflammatory response with leukotrienes or prostaglandins facilitating the action potential in the PAN. In addition to the arachidonic cascade, many chemicals activate the PAN when they leak out of the cell or are released into the intracellular space as part of the inflammatory response. For example, potassium and histamine exude from damaged cells, and bradykinin is degraded from plasma kininogen, a component of inflammatory exudate. Other chemicals are released from platelets (serotonin) or mast cells (histamine). Sufficient concentrations of any of these chemicals around the PAN will cause the PAN to be transduced with the action potential then transmitted to the spinal dorsal horn. These chemicals also act in combination to sensitize the PAN, enabling it to fire with a stimulus smaller than usual. Furthermore, if the PAN is transduced and an action potential is initiated, the PAN itself releases chemicals, one of which is substance P. Substance P is stored in the distal terminals of the PAN and is released through a retrograde process. In this way, substance $\mathrm{P}$ sensitizes the PAN, dilates nearby blood vessels, which leads to local edema and causes release of histamine from mast cells. In summary, tissue injury (due to vaso-occlusion events or inflammation) results in production and release of a number of chemicals around the PAN. These chemicals can sensitize or transduce the PAN directly (example of nociceptive pain) and through secondary processes (usually an example of nociceptive pain unless neural tissue has been injured, then an example of neuropathic pain). These chemicals are commonly described as ingredients in the peripheral milieu surrounding the PAN. If any or all of these ingredients can be eliminated from the peripheral milieu, then the PAN action potential may not be transmitted to the CNS. A number of non-opioid analgesics inhibit these chemicals and thereby remove peripheral soup ingredients that contribute to PAN activation. Drugs that block production or release of these chemicals can be powerful analgesics and are the first line drugs recommended for pain therapy (Table 1).

\section{Central sensitization leading to neuropathic pain}

Significant CNS neuroplasticity occurs after neuronal damage, resulting in central sensitization. ${ }^{4,9}$ Central sensitization requires, in part, the activation of the N-methyl-Daspartate (NMDA) receptors since the development of the sensitized state can be blocked by NMDA receptor antagonists. ${ }^{9}$ The NMDA receptor is a ligand-gated ion channel that is open when the receptor is bound to glutamate and the membrane is sufficiently depolarized. The latter is required for the dissociation of the $\mathrm{Mg}^{2+}$ that sits in the pore and blocks the channel at the resting state. The activated NMDA receptor is highly permeable to the influx of $\mathrm{Ca}^{2+}$. It has also been demonstrated that NMDA receptor antagonists (competitive or noncompetitive) administered prior to inflammatory pain or peripheral nerve injuries suppress or delay the onset of hyperalgesia and attenuate fully developed hyperalgesia when administered after the injury. ${ }^{10}$ Interestingly, magnesium has been reported to be beneficial for SCD pain. ${ }^{11,12}$ Activation of the NMDA receptor and subsequent activation of nitric oxide synthase (NOS) through $\mathrm{Ca}^{2+}$ influx and $\mathrm{Ca}^{2+} / \mathrm{CaM}$ dependent pathway is well established. ${ }^{13}$ Inhibitors of NOS have been consistently shown to be effective in different chronic pain models. ${ }^{14-16}$ The NOS/NO pathway is particular relevant for SCD, although one must proceed with caution as NO may be beneficial and harmful in SCD. Among the three isoforms of NOS: neuronal (nNOS), endothelial (eNOS), and inducible nitric oxide synthase (iNOS), nNOS is the most important for pain. Pharmacological intervention of pain in SCD should be focused on inhibiting nNOS. ${ }^{17}$ The source leading to and maintaining the activation of the NMDA receptor complex during the development of neuropathic pain is uncertain. Persistent activation of the NMDA receptors through receptor phosphorylation has been proposed, since the NMDA receptor can be phosphorylated and activated by several protein kinases including protein kinase $\mathrm{C}$ (PKC) and $\mathrm{Ca}^{2+} /$ calmodulin-dependent protein kinase II (CaMKII). In addition, PKC can activate the NMDA receptor by reducing $\mathrm{Mg}^{2+}$ blockade. 


\section{Protein kinase $\mathrm{C}$ and neuropathic pain}

Protein kinase $\mathrm{C}(\mathrm{PKC})$ regulates the function of a variety of substrates by phosphorylation. This enzyme is involved in diverse cellular processes, from cell differentiation and proliferation, to long term potentiation of neuronal activity. Members of PKC kinases are classified into three groups based on their primary structure and co-factors for activation. The conventional PKC group includes PKCa, $\beta_{\mathrm{I}}, \beta_{\mathrm{II}}$, and $\gamma$, which are activated by calcium and phosphatidylserine. In contrast, the novel PKCs, including $\delta, \varepsilon, \eta \eta$, and $\theta$, do not require calcium for activation. PKC $\zeta$ and $\imath$ (human homologue of murine $\lambda$ ) belong to the class of atypical PKC, which are activated by a yet to be defined mechanism. PKC has been found to translocate to the membrane upon influx of $\mathrm{Ca}^{2+}$. Protein kinase inhibitors, including those relatively selective for PKC, have been shown to block behavioral signs of pain in animal models. More specifically, studies have linked isoforms of PKC with pain. $\mathrm{PKC} \gamma$ immunoreactivity was reported to be increased after peripheral nerve injury and inflammation. ${ }^{18}$ In null mutants of PKC $\gamma$, nerve injury-induced allodynia and thermal hyperalgesia were largely absent. ${ }^{19}$ However, PKC $\gamma$ is not the only isoform involved in neuropathic pain. Epinephrine- or acetic acid-induced hyperalgesia was markedly attenuated in mice lacking the PKC $\varepsilon$ gene. ${ }^{20}$ The NMDA receptor-mediated currents are potentiated by PKC and PKC activators. ${ }^{21}$ The activated NMDA receptors are permeable to $\mathrm{Ca}^{2+}$, which, in turn, can activate PKC. Therefore, a positive feed-forward loop between PKC and the NMDA receptors may exist (Figure 2), although such a mechanism has yet to be tested directly in neuropathic pain.

\section{$\mathrm{Ca}^{2+} /$ calmodulin-dependent protein kinase Ila (CaMKIla) and pain}

$\mathrm{CaMKII}$ is a multifunctional, $\mathrm{Ca}^{2+} /$ calumodulin $(\mathrm{CaM})$ activated serine/threonine protein kinase that is a key component of intracellular $\mathrm{Ca}^{2+}$ signaling pathways. ${ }^{22}$ Upon a significant increase in intracellular $\mathrm{Ca}^{2+}$ levels, calmodulin is activated by a conformational change after its binding to $\mathrm{Ca}^{2+}$ at the $\mathrm{Ca}^{2+}$-binding sites. This binding, in turn, leads to the activation of CaMKII when the latter is bound with $\mathrm{Ca}^{2+} / \mathrm{CaM}$. A key step in CaMKII activation is the autophosphorylation of threonine $286 / 287$ upon the binding of $\mathrm{Ca}^{2+} / \mathrm{CaM}$. The autophosphorylation renders the kinase fully active and it can remain active even after the $\mathrm{Ca}^{2+}$ has subsided.

CaMKII is ubiquitously distributed in the CNS and accounts for approximately $1-2 \%$ of total brain protein mass. Four different CaMKII isoforms, $\alpha, \beta, \delta$, and $\gamma$, have high sequence homology in the amino-terminal catalytic/regulatory domains and the carboxylterminal association domain respectively. The association domain is responsible for the formation of a holoenzyme complex by $10-12$ individual CaMKII proteins. ${ }^{23}$ In this kinase family, CaMKIIa is the most extensively studied isoform that has been found to regulate synapse transduction by phosphorylating ion channels and signal transduction molecules at post synaptic density. ${ }^{22}$

Both the release of $\mathrm{Ca}^{2+}$ from intracellular storages and $\mathrm{Ca}^{2+}$ influx as a result of receptor or ion channel activation can activate calmodulin and CaMKII. Activation of the transient receptor potential vanilloid 1 receptor (TRPV1) or the NMDA receptors will both lead to $\mathrm{Ca}^{2+}$ influx and CaMKII activation. The unique interaction between CaMKII and NMDA receptors is intriguing and may serve as a mechanism for long lasting plasticity in neuropathic pain. CaMKII phosphorylates the NMDA receptor, leading to receptor activation. $\mathrm{Ca}^{2+}$ influx through the activation of the NMDA receptors, in turn, activates $\mathrm{CaM}$ and leads to the autophosphorylation and subsequent full activation of CaMKII. Therefore, a positive feed-forward loop keeps the pathways active after the original $\mathrm{Ca}^{2+}$ signaling has subsided or disappeared. Indeed inflammatory pain and nerve injury have been 
shown to increase levels of glutamate in the spinal dorsal horn, which was blocked by NMDA receptor antagonists. ${ }^{10}$ Overexpression of the NR2B subunit of the NMDA receptor causes increased mechanical allodynia in conditions with inflammatory pain, whereas inhibition of NR2B ${ }^{24}$ or knockdown of spinal NMDA receptors with antisense oligonucleotides ${ }^{25}$ prevents the expression of chemically induced hyperalgesia. Therefore, CaMKII may work in concert with the NMDA receptors in the development and maintenance of the neural events leading to hyperalgesia.

In the spinal cord and the primary afferent, CaMKIIa is specifically expressed in the superficial laminae of the spinal dorsal horn and in the small to medium diameter primary sensory neurons in dorsal root ganglia, where nociceptive signals are transmitted and processed. ${ }^{26,27}$ Willis and colleagues reported that CaMKIIa activity was increased significantly in the spinal cord within minutes after an intradermal injection of capsaicin. ${ }^{28}$ In addition, spinally administered CaMKII inhibitor KN93, but not inactive analog KN92, inhibited the enhancement of responses of spinal nociceptive neurons and changes in exploratory behavior evoked by capsaicin injection. ${ }^{28}$ In rat trigeminal ganglion neurons, Hargreaves and colleagues found that capsaicin increased CaMKII activity in TRPV1positive neurons. ${ }^{29}$ In these trigeminal ganglion neurons, capsaicin- or $\mathrm{n}$-arachidonoyldopamine (NADA)-evoked calcitonin gene-related peptide (CGRP) release was inhibited by KN93. ${ }^{29}$ These data suggest that there is a functional interaction between CaMKII and TRPV1. Mechanistically, CaMKII phosphorylates TRPV1, thereby regulating TRPV1 activity. TRPV1 regulates the $\mathrm{Ca}^{2+}$-influx and intracellular $\mathrm{Ca}^{2+}$-levels, thereby affecting CaMKII activity. ${ }^{30}$ Therefore, there may be a functional interaction between CaMKII and TRPV1, similar to that between CaMKII and the NMDA receptor complex (Fig. 2).

The role of CaMKIIa in persistent inflammatory or neuropathic pain has also been suggested. One group found that CaMKII inhibitors at very low doses reversed chronic nerve constriction injury (CCI)-induced neuropathic pain in mice, although the exact experimental details were not provided. ${ }^{25}$ In other studies, investigators reported mixed effects that KN93 prevented, but did not reverse, thermal hyperalgesia and mechanical allodynia following CCI. ${ }^{10}$ We have reported a critical role of CaMKII in complete Freund's adjuvant (CFA)-induced hyperalgesia pain, ${ }^{31}$ spinal nerve ligation-induced neuropathic pain behaviors, ${ }^{32}$ and opioid-induced hyperalgesia. ${ }^{33}$ In summary, CaMKIIa appeared to be a critical regulator of central sensitization leading to many, if not all, types of chronic pain.

\section{Neurobiological mechanisms of sickle cell pain}

Early studies on the molecular mechanisms of neuropathic pain were hindered by the lack of suitable models until several experimental neuropathic injury models were developed in rodents. ${ }^{36}$ Since then, these models have been used extensively to examine the neuroanatomical and neurochemical changes in the spinal cord and other CNS regions that contribute to the development and maintenance of neuropathic pain. We have seen similar limitations in the study of pain in SCD. However, SCD transgenic mice models have emerged to be suitable models for the disease and for the study of SCD pain.

The first generation SCD mouse model is transgenic expressing human $a$ and $\beta^{S}$ globin transgenes without deletion of endogenous mouse $\alpha$ and $\beta$ genes. ${ }^{37}$ Limited red cell sickling was observed in these mice in vivo. ${ }^{38}$ In order to enhance red cell sickling, a $\beta$ globin gene with three mutations (designated SAD) was introduced..$^{39}$ Additional mouse models have been produced to yield models with varying severity hemolytic anemia and other symptoms of SCD. ${ }^{37}$ A major breakthrough came when SCD mouse lines were made to carry exclusively human globins by "knocking out" mouse globins genes. ${ }^{40-42}$ Among these mouse models of SCD, Berkeley sickle cell transgenic mice express exclusively human sickle hemoglobin and have a phenotype that closely mimics many features of severe SCD 
in humans, including severe hemolytic anemia, irreversibly sickled red cells, increased rigidity of erythrocytes, and extensive multiple organ damage. ${ }^{43}$ Additional similarities to human disease include vascular ectasia, intravascular hemolysis, exuberant hematopoiesis, cardiomegaly, glomerulosclerosis, visceral congestion, hemorrhages, multiorgan infarcts, pyknotic neurons, progressive siderosis, gallstones, and priapism. ${ }^{44}$ Littermates mice that are heterozygous for Hbb gene do not develop hemolytic anemia and other SCD characteristic. $^{44}$

The NY1DD mice, having mild SCD pathology and no hemolysis, have been studied for pain behaviors. In a thermal nociception test where radiant heat was applied to the dorsal side of the tail, the latency to a rapid tail-flick response was compared between NY1DD mice and C57B1/6 control mice. At 10 weeks of age, NY1DD mice showed a more rapid tail-flick response $(\mathrm{p}<0.0001)$, suggesting the presence of thermal hyperalgesia. At 6 weeks of age, however, the latencies exhibited by the two groups of mice were not different. These data suggest that NY1DD sickle cell mice have an age-dependent onset of thermal hyperalgesia. ${ }^{45}$

In our ongoing studies of Berkeley sickle cell mice, we have employed assays that are predominately designed to detect neuropathic pain, including cold allodynia, heat hyperalgesia, and mechanical allodynia. We observed significantly enhanced pain response and decreased nociception threshold that persist for at least 4 months in Berkeley sickle cell mice when compared with littermate non-sickle mice (Chen, Wang et al, unpublished observations). These data are in agreement with our clinical finding for the presence of neuropathic pain in adult humans with SCD. ${ }^{46}$ Moreover, we found that PKC and CaMKII activation was significantly increased in the spinal doral horn neurons, which was similar to what we have observed in other chronic pain states. ${ }^{31-33}$

\section{Summary}

Intriguing evidence from adults with SCD and transgenic sickle cell mice challenges the existing assumptions about pain in SCD. Whereas pain of SCD has been thought to be related to visceral and somatic tissue injury subsequent to vaso-occlusion events, another component of pain of SCD may be related to neuropathic processes. Some of the mechanisms related to neuropathic pain involve CaMKII and PKC, which may be relevant to the pain of SCD. Our group is characterizing the mechanisms of pain in Berkeley transgenic sickle cell mice. As well, we are characterizing thermal and mechanical allodynia and hyperalgesia in adult patients with SCD. Timely with the 100-year anniversary of scientific documentation of SCD, the insights from these studies will offer important evidence about the role of neuropathic pain in SCD.

\section{Acknowledgments}

This publication was made possible by National Institutes of Health grants R01 HL098141, R01 HL078536, and K07 AT003647. Its contents are solely the responsibility of the authors and do not necessarily represent the official views of the National Institutes of Health, National Heart Lung and Blood Institute, or National Center for Complimentary and Alternative Medicine. The final peer-reviewed manuscript is subject to the National Institutes of Health Public Access Policy.

\section{References}

1. Herrick JB. Peculiar elongated and sickle-shaped red blood corpuscles in a case of severe anemia. 1910. Arch Int Med. 1910; 6:517-521.

2. Merskey, H.; Bogduk, N., editors. Classification of Chronic pain: Descriptions of Chronic Pain Syndromes and Definitions of Pain Terms. 2. Seattle, WA: IASP Press; 1994. 
3. Basbaum AI, Bautista DM, Scherrer G, Julius D. Cellular and molecular mechanisms of pain. Cell. 2009; 139:267-284. [PubMed: 19837031]

4. Costigan M, Scholz J, Woolf CJ. Neuropathic pain: a maladaptive response of the nervous system to damage. Annu Rev Neurosci. 2009; 32:1-32. [PubMed: 19400724]

5. Milligan ED, Watkins LR. Pathological and protective roles of glia in chronic pain. Nat Rev Neurosci. 2009; 10:23-36. [PubMed: 19096368]

6. Platt OS, Thorington BD, Brambilla DJ, et al. Pain in sickle cell disease. Rates and risk factors. N Engl J Med. 1991; 325:11-16. [PubMed: 1710777]

7. Ballas SK, Lusardi M. Hospital readmission for adult acute sickle cell painful episodes: frequency, etiology, and prognostic significance. Am J Hematol. 2005; 79:17-25. [PubMed: 15849770]

8. Smith WR, Penberthy LT, Bovbjerg VE, et al. Daily assessment of pain in adults with sickle cell disease. Ann Intern Med. 2008; 148:94-101. [PubMed: 18195334]

9. Latremoliere A, Woolf CJ. Central sensitization: a generator of pain hypersensitivity by central neural plasticity. J Pain. 2009; 10:895-926. [PubMed: 19712899]

10. Dai Y, Wang H, Ogawa A, et al. Ca2+/calmodulin-dependent protein kinase II in the spinal cord contributes to neuropathic pain in a rat model of mononeuropathy. Eur J Neurosci. 2005; 21:24672474. [PubMed: 15932604]

11. Brousseau DC, Scott JP, Hillery CA, Panepinto JA. The effect of magnesium on length of stay for pediatric sickle cell pain crisis. Acad Emerg Med. 2004; 11:968-972. [PubMed: 15347549]

12. Hankins JS, Wynn LW, Brugnara C, Hillery CA, Li CS, Wang WC. Phase I study of magnesium pidolate in combination with hydroxycarbamide for children with sickle cell anaemia. Br J Haematol. 2008; 140:80-85. [PubMed: 17991298]

13. Bredt DS, Snyder SH. Nitric oxide, a novel neuronal messenger. Neuron. 1992; 8:3-11. [PubMed: 1370373]

14. Elliott K, Kest B, Man A, Kao B, Inturrisi CE. N-methyl-D-aspartate (NMDA) receptors, mu and kappa opioid tolerance, and perspectives on new analgesic drug development. Neuropsychopharmacology. 1995; 13:347-356. [PubMed: 8747759]

15. Olesen J, Jansen-Olesen I. Nitric oxide mechanisms in migraine. Pathol Biol (Paris). 2000; 48:648-657. [PubMed: 11072643]

16. Freire MA, Guimaraes JS, Leal WG, Pereira A. Pain modulation by nitric oxide in the spinal cord. Front Neurosci. 2009; 3:175-181. [PubMed: 20011139]

17. Salerno L, Sorrenti V, Di Giacomo C, Romeo G, Siracusa MA. Progress in the development of selective nitric oxide synthase (NOS) inhibitors. Curr Pharm Des. 2002; 8:177-200. [PubMed: 11812267]

18. Mao J, Price DD, Mayer DJ. Mechanisms of hyperalgesia and morphine tolerance: a current view of their possible interactions. Pain. 1995; 62:259-274. [PubMed: 8657426]

19. Malmberg AB, Chen C, Tonegawa S, Basbaum AI. Preserved acute pain and reduced neuropathic pain in mice lacking PKCgamma. Science. 1997; 278:279-283. [PubMed: 9323205]

20. Khasar SG, McCarter G, Levine JD. Epinephrine produces a beta-adrenergic receptor-mediated mechanical hyperalgesia and in vitro sensitization of rat nociceptors. J Neurophysiol. 1999; 81:1104-1112. [PubMed: 10085337]

21. Wang ZJ, Wang LX. Phosphorylation: a molecular switch in opioid tolerance. Life Sci. 2006; 79:1681-1691. [PubMed: 16831450]

22. Colbran RJ. Targeting of calcium/calmodulin-dependent protein kinase II. Biochem J. 2004; 378:1-16. [PubMed: 14653781]

23. Takeuchi Y, Fukunaga K, Miyamoto E. Activation of nuclear $\mathrm{Ca}(2+) /$ calmodulin-dependent protein kinase II and brain-derived neurotrophic factor gene expression by stimulation of dopamine D2 receptor in transfected NG108-15 cells. J Neurochem. 2002; 82:316-328. [PubMed: 12124432]

24. Qu XX, Cai J, Li MJ, et al. Role of the spinal cord NR2B-containing NMDA receptors in the development of neuropathic pain. Exp Neurol. 2009; 215:298-307. [PubMed: 19046970]

25. Garry MG, Malik S, Yu J, Davis MA, Yang J. Knock down of spinal NMDA receptors reduces NMDA and formalin evoked behaviors in rat. Neuroreport. 2000; 11:49-55. [PubMed: 10683828] 
26. Bruggemann I, Schulz S, Wiborny D, Hollt V. Colocalization of the mu-opioid receptor and calcium/calmodulin-dependent kinase II in distinct pain-processing brain regions. Brain Res Mol Brain Res. 2000; 85:239-250. [PubMed: 11146127]

27. Carlton SM. Localization of CaMKIIalpha in rat primary sensory neurons: increase in inflammation. Brain Res. 2002; 947:252-259. [PubMed: 12176168]

28. Fang L, Wu J, Lin Q, Willis WD. Calcium-calmodulin-dependent protein kinase II contributes to spinal cord central sensitization. J Neurosci. 2002; 22:4196-4204. [PubMed: 12019337]

29. Price TJ, Jeske NA, Flores CM, Hargreaves KM. Pharmacological interactions between calcium/ calmodulin-dependent kinase II alpha and TRPV1 receptors in rat trigeminal sensory neurons. Neurosci Lett. 2005; 389:94-98. [PubMed: 16095822]

30. Jones TL, Lustig AC, Sorkin LS. Secondary hyperalgesia in the postoperative pain model is dependent on spinal calcium/calmodulin-dependent protein kinase II alpha activation. Anesth Analg. 2007; 105:1650-1656. table of contents. [PubMed: 18042863]

31. Luo F, Yang C, Chen Y, et al. Reversal of chronic inflammatory pain by acute inhibition of $\mathrm{Ca} 2+/$ calmodulin-dependent protein kinase II. J Pharmacol Exp Ther. 2008; 325:267-275. [PubMed: 18178903]

32. Chen Y, Luo F, Yang C, Kirkmire CM, Wang ZJ. Acute inhibition of Ca2+/calmodulin-dependent protein kinase II reverses experimental neuropathic pain in mice. J Pharmacol Exp Ther. 2009; 330:650-659. [PubMed: 19478130]

33. Chen Y, Yang C, Wang ZJ. Ca2+/calmodulin-dependent protein kinase II alpha is required for the initiation and maintenance of opioid-induced hyperalgesia. J Neurosci. 2010; 30:38-46. [PubMed: 20053885]

34. Zeitz KP, Giese KP, Silva AJ, Basbaum AI. The contribution of autophosphorylated alphacalcium-calmodulin kinase II to injury-induced persistent pain. Neuroscience. 2004; 128:889-898. [PubMed: 15464294]

35. Jones TL, Sorkin LS. Activated PKA and PKC, but not CaMKIIalpha, are required for AMPA/ Kainate-mediated pain behavior in the thermal stimulus model. Pain. 2005; 117:259-270. [PubMed: 16150547]

36. Wang LX, Wang ZJ. Animal and cellular models of chronic pain. Adv Drug Deliv Rev. 2003; 55:949-965. [PubMed: 12935939]

37. Nagel RL, Fabry ME. The panoply of animal models for sickle cell anaemia. Br J Haematol. 2001; 112:19-25. [PubMed: 11167777]

38. Fabry ME, Costantini F, Pachnis A, et al. High expression of human beta S- and alpha-globins in transgenic mice: erythrocyte abnormalities, organ damage, and the effect of hypoxia. Proc Natl Acad Sci U S A. 1992; 89:12155-12159. [PubMed: 1465455]

39. Trudel M, Garel MC, Saadane N, et al. Towards a mouse model for sickle cell disease: HB SAD. Nouv Rev Fr Hematol. 1990; 32:407-408. [PubMed: 2101873]

40. Ryan TM, Ciavatta DJ, Townes TM. Knockout-transgenic mouse model of sickle cell disease. Science. 1997; 278:873-876. [PubMed: 9346487]

41. Paszty C, Brion CM, Manci E, et al. Transgenic knockout mice with exclusively human sickle hemoglobin and sickle cell disease. Science. 1997; 278:876-878. [PubMed: 9346488]

42. Chang JC, Lu R, Lin C, et al. Transgenic knockout mice exclusively expressing human hemoglobin S after transfer of a 240-kb betas-globin yeast artificial chromosome: A mouse model of sickle cell anemia. Proc Natl Acad Sci U S A. 1998; 95:14886-14890. [PubMed: 9843985]

43. Paszty C. Transgenic and gene knock-out mouse models of sickle cell anemia and the thalassemias. Curr Opin Hematol. 1997; 4:88-93. [PubMed: 9107524]

44. Manci EA, Hillery CA, Bodian CA, Zhang ZG, Lutty GA, Coller BS. Pathology of Berkeley sickle cell mice: similarities and differences with human sickle cell disease. Blood. 2006; 107:16511658. [PubMed: 16166585]

45. Lunzer MM, Yekkirala A, Hebbel RP, Portoghese PS. Naloxone acts as a potent analgesic in transgenic mouse models of sickle cell anemia. Proc Natl Acad Sci U S A. 2007; 104:6061-6065. [PubMed: 17389363] 
46. Wilkie DJ, Molokie R, Boyd-Seal D, et al. Patient-reported outcomes: descriptors of nociceptive and neuropathic pain and barriers to effective pain management in adult outpatients with sickle cell disease. J Natl Med Assoc. 102:18-27. [PubMed: 20158132] 


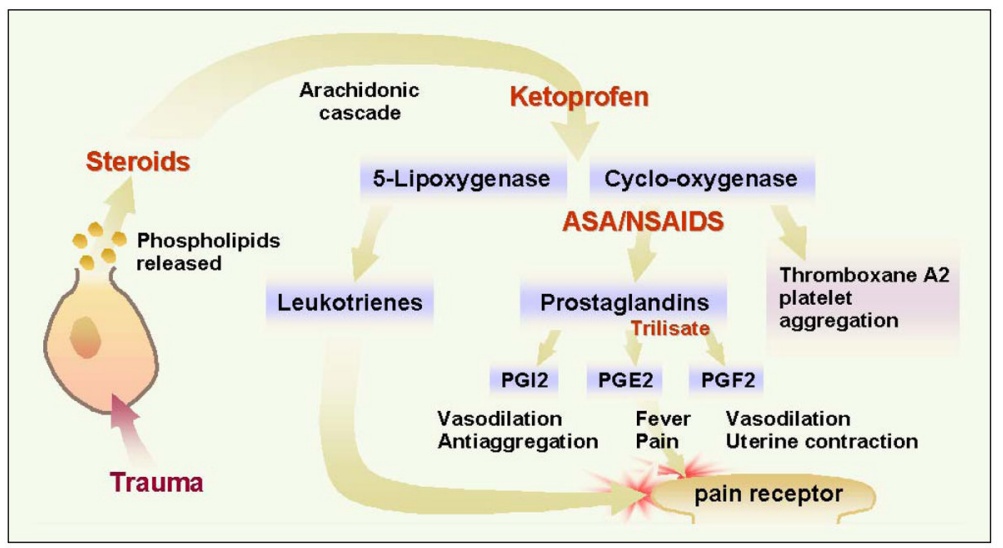

Figure 1. Inhibition of the arachidonic acid pathway by several drugs

Steroids inhibit production of arachidonic acid, thereby blocking synthesis of leukotrienes and prostaglandins. Ketoprophen is believed to block production of 5-lipooxygenase and cyclooxygenase. Aspirin and nonsteroidal anti-inflammatory drugs block conversion of cyclo-oxygenase to prostaglandins and thromboxane $\mathrm{A}_{2}$. Trilisate blocks production of prostagandins $(\mathrm{PG}) \mathrm{E}_{2}$ and $\mathrm{F}_{2}$, but not $\mathrm{I}_{2}$ or thromboxane $\mathrm{A}_{2}$. (C) 2001 D.J. Wilkie, used with permission. 


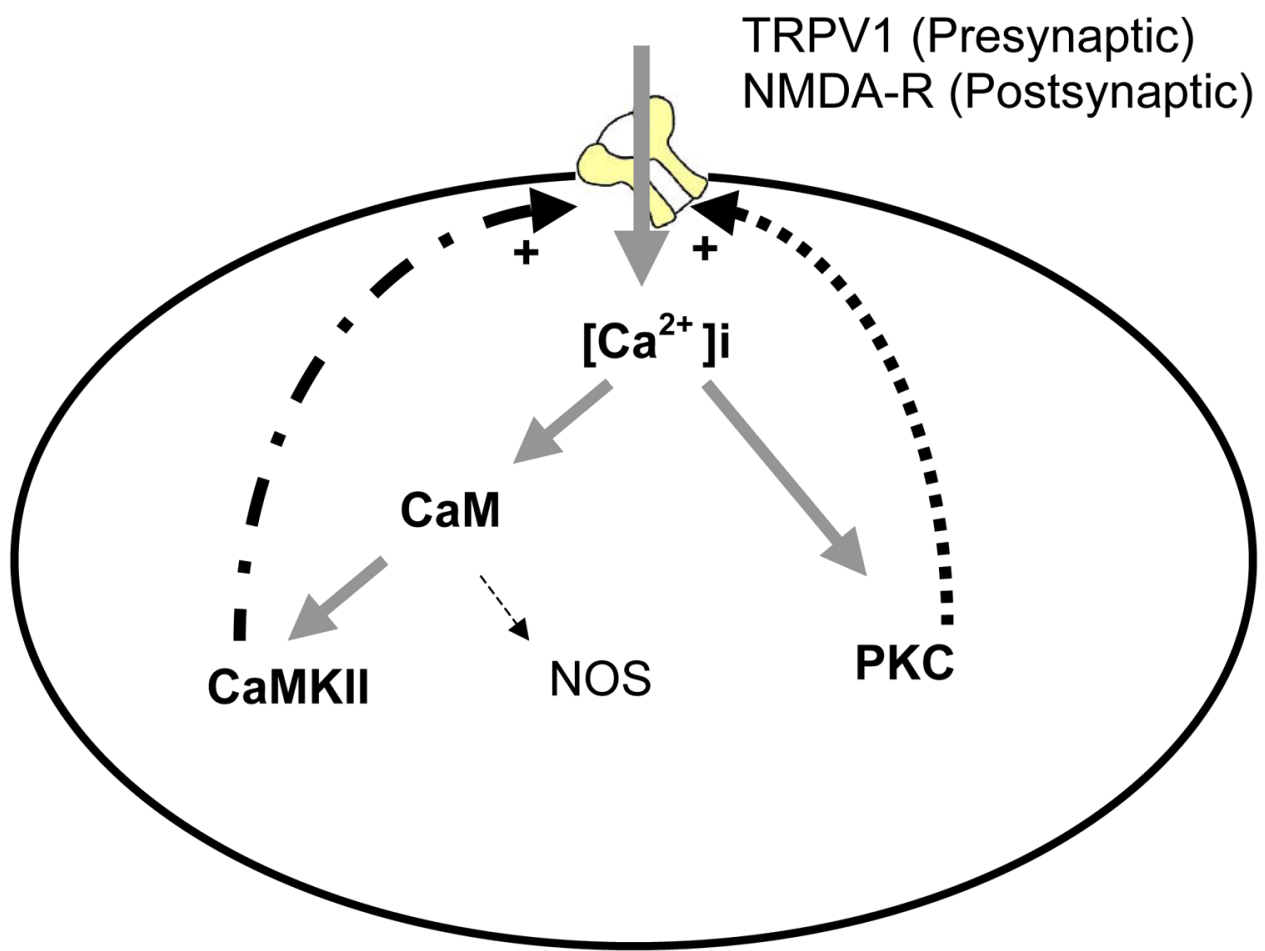

Figure 2. Positive feed-forward loops involving PKC and CaMKII in neuropathic pain This is a simplified scheme demonstrating the persistent activation of protein kinase $\mathrm{C}$ (PKC) and $\mathrm{Ca}^{2+} /$ calmodulin (CaM)-dependent protein kinase II (CaMKII) in neuropathic pain. $\mathrm{Ca}^{2+}$ influx through the activation of the N-methyl-D-aspartate (NMDA) receptors or the transient receptor potential vanilloid 1 receptor (TRPV1) leads to increased intracellular $\mathrm{Ca}^{2+}$ levels and subsequent activation of PKC and CaMKII. Both PKC and CaMKII can activate the NMDA receptors or TRPV1 via phosphorylation. Such feed-forward mechanisms may be one way for the sustained activation PKC or CaMKII in neuropathic pain. It is likely additional mechanisms can activate and/or sustain the activation of PKC and CaMKII, for example, by activating a Gq coupled receptor or through $\mathrm{Ca}^{2+}$ release from the intracellular storage. It should be noted that PKC and CaMKII do not need to be coexpressed or simultaneously activated in a single cell. Whereas the NMDA receptors are expressed in the post-synaptic neurons, the TRPV1 may play a major role in pre-synatic neurons. For downstream signal transduction, these protein kinases phosphorylate numerous effectors including transcription factors, receptors, and ion channels. Key: $\mathrm{Ca}^{2+}=$ calcium; $\mathrm{CaM}=$ calmodulin; $\mathrm{CaMKII}=\mathrm{Ca}^{2+} /$ calmodulin-dependent protein kinase $\mathrm{II}$; NMDA-R $=$ the $\mathrm{N}$-methyl-D-aspartate receptor; $\mathrm{NOS}=$ nitric oxide synthase; $\mathrm{PKC}=$ protein kinase $\mathrm{C}$; TRPV1= the transient receptor potential vanilloid 1 receptor. 
Table 1

Neural Mechanisms of Pain: Facilitating and Inhibiting Factors

\begin{tabular}{|c|c|c|c|}
\hline Anatomical Structure & $\begin{array}{l}\text { Neurotransmitters, } \\
\text { Neurochemicals or } \\
\text { Receptors }\end{array}$ & $\begin{array}{l}\text { Modulatory Effect on } \\
\text { Transduction or } \\
\text { Transmission (F: } \\
\text { Facilitation; I: Inhibition }\end{array}$ & $\begin{array}{l}\text { Examples of modulating Drugs } \\
\text { (Inhibit facilitation or enhance } \\
\text { inhibition of pain transduction or } \\
\text { transmission) }\end{array}$ \\
\hline $\begin{array}{l}\text { Peripheral Nervous System } \\
\text { PAN Terminal }\end{array}$ & $\begin{array}{l}\text { Leukotriene } \\
\text { Prostaglandins } \\
\text { Potassium } \\
\text { Histamine } \\
\text { Bradykinin } \\
\text { Serotonin } \\
\text { Substance P } \\
\text { Endorphin }\end{array}$ & $\begin{array}{l}\text { Transduction } \\
\text { F, sensitizes } \\
\text { F, sensitizes } \\
\text { F, sensitizes } \\
\text { F, sensitizes } \\
\text { F, sensitizes } \\
\text { F, sensitizes } \\
\text { F, sensitizes } \\
\text { I }\end{array}$ & $\begin{array}{l}\text { corticosteroids, ketoprofen } \\
\text { NSAIDs, e.g., ASA } \\
\text { n/a } \\
\text { antihistamines } \\
\text { n/a } \\
\text { n/a } \\
\text { n/a } \\
\text { opioids }\end{array}$ \\
\hline Fiber & $\begin{array}{l}\mathrm{Na}+, \mathrm{K}+\text { exchange across the } \\
\text { cellular membrane }\end{array}$ & $\begin{array}{l}\text { F, Transmission of action } \\
\text { potential to CNS }\end{array}$ & mexiletine, tocainide, EMLA \\
\hline Autonomic Nervous System & Norepinephrine & $\begin{array}{l}\text { Transduction } \\
\text { F, sensitizes nociceptive state } \\
\text { F, activates neuropathic state }\end{array}$ & anxiolytics \\
\hline Spinal Cord & $\begin{array}{l}\text { Substance } \mathrm{P} \text {, glutamate, and } \\
\text { others } \\
\text { serotonin }\left(5 \mathrm{HT}_{1 \mathrm{~B}} \text { and } 5 \mathrm{HT}_{3}\right) \\
\text { norepinephrine } \\
\text { mu } \\
\text { delta } \\
\text { kappa } \\
\mathrm{GABA}_{\mathrm{A}} \\
\mathrm{GABA}_{\mathrm{B}}\end{array}$ & $\begin{array}{l}\text { F, Transmission to projection } \\
\left.\text { cell ( } 2^{\text {nd }} \text { order neuron }\right) \\
\text { F, Transmission with wind-up }\end{array}$ & $\begin{array}{l}\text { opioids } \\
\text { ketamine } \\
\text { dextromethorphan } \\
\text { TCAs } \\
\text { TCAs, clonidine } \\
\text { opioid agonists (e.g. morphine) } \\
\text { opioid agonists } \\
\text { opioid antagonist-agonists } \\
\text { benzodiazepines } \\
\text { baclofen }\end{array}$ \\
\hline Brain & $\begin{array}{l}\text { Substance P, glutamate, and } \\
\text { others }\end{array}$ & $\begin{array}{l}\text { F, Transmission to } 3^{\text {rd }} \text { or } 4^{\text {th }} \\
\text { order neuron }\end{array}$ & opioids \\
\hline
\end{tabular}

Key: PAN=primary afferent nociceptor; ASA=aspirin; NSAIDs=nonsteroidal antiinflammatory drugs; $\mathrm{n} / \mathrm{a}=$ not available or not applicable; Na +=sodium; $\mathrm{K}+=$ potassium; $\mathrm{CNS}=$ central nervous system; TCAs=tricyclic antidepressant drugs or other re-uptake inhibitor drugs. () 2001 D.J. Wilkie, used with permission. 